\title{
Markers of Chronic Inflammation in Overweight and Obese Individuals and the Role of Gender: A Cross-Sectional Study of a Large Cohort
}

This article was published in the following Dove Press journal: Journal of Inflammation Research

\author{
Eytan Cohen ${ }^{1,2}$ \\ Ili Margalit ${ }^{1,2}$ \\ Tzippy Shochat ${ }^{3}$ \\ Elad Goldberg ${ }^{1,2}$ \\ Ilan Krause ${ }^{1,2}$
}

'Department of Medicine F - Recanati, Rabin Medical Center - Beilinson Hospital, Petach Tikva, Israel; ${ }^{2}$ Sackler Faculty of Medicine, Tel Aviv University, Ramat Aviv, Israel; ${ }^{3}$ Statistical Counselling Unit, Rabin Medical Center - Beilinson Hospital, Petach Tikva, Israel
Correspondence: Eytan Cohen Department of Medicine F - Recanati, Rabin Medical Center - Beilinson Hospital, Petach Tikva, 494I492, Israel Tel +972-3-937736 I

Fax +972-3-9244663

Email dreytancohen@gmail.com
Objective: During the last decade, obesity has become an epidemic. As obesity is now considered a state of low-grade inflammation, the purpose of this study was to assess the prevalence of four common elements of inflammation, in individuals with increased BMI. These findings were compared to those of subjects with normal BMI. The effect of gender was also noted.

Methods: Data were collected from medical records of individuals examined at a screening center in Israel between the years 2000-2014. Cross-sectional analysis was carried out on 7526 men and 3219 women. White blood cell count (WBC); platelet (PLT) count; erythrocyte sedimentation rate (ESR) and C-reactive protein (CRP) were assessed in four BMI categories: normal, overweight, obese and morbidly obese.

Results: Mean (SD) age of the study sample was 47.5 (9.7) and 46.7 (9.8) years for men and women, respectively. The prevalence of each inflammatory marker increased significantly when comparing abnormal to normal BMI $(\mathrm{p}<0.0001)$. The odds ratio $(\mathrm{OR})$ of the prevalence of increased inflammatory markers was compared between subjects with overweight, obese and morbid obesity and subjects with normal BMI. This study showed that the higher the BMI, the higher the OR. For those in the morbid obesity group, the OR for the different inflammatory markers adjusting for age, diabetes mellitus hypertension and kidney function were as follows: WBC levels, 5.1 (2.9-8.7) and 4.7 (2.4-9.1) for men and women, respectively; PLT levels, $1.7(0.3-8.5)$ and $2.0(0.6-7.2)$ for men and women, respectively; ESR levels, 4.2 (3.2-5.4) and 4.6 (3.2-6.6) for men and women, respectively, and CRP levels, 13.4 (10.0-18.2) and 19.2 (12.9-28.6) for men and women, respectively.

Conclusion: Inflammatory markers are significantly higher in subjects with abnormal compared to normal BMI. This difference was found to be greater in women than in men.

Keywords: gender, inflammatory markers, body mass index

\section{Introduction}

Overweight and obesity have become global epidemics. The latest estimates in the USA are that approximately $68 \%$ of adults are either overweight or obese, with $34 \%$ being obese. ${ }^{1}$ Several acute phase reactants such as fibrinogen, CRP, complement, serum amyloid $\mathrm{A}$ and haptoglobin ${ }^{2}$ are produced by the liver and regulated by cytokines including IL-6 and TNF-alpha. ${ }^{3-5}$ These pro-inflammatory cytokines can be found in healthy obese subjects. ${ }^{6-8}$ Interestingly, recent studies have shown that bariatric surgery decreases the levels of many of the inflammatory factors. 9,10 
The relationship between inflammatory markers and obesity may be influenced by gender. This is attributed to different fat disposition among men and women and to the influence of sex hormones. ${ }^{11}$

Several other commonly used laboratory tests may be associated with the state of inflammation. These tests include the levels of white blood cells (WBC), platelets, erythrocyte sedimentation rate (ESR) and $\mathrm{C}$ reactive protein (CRP). Indeed, several studies have correlated obesity and these inflammatory markers; this has been shown for WBC, ${ }^{12}$ platelet count, ${ }^{13} \mathrm{ESR}^{14}$ and CRP. ${ }^{15-17}$ Most of these studies, however, included a relatively small number of obese subjects and did not assess the correlation of inflammatory markers for the overweight subgroup. Nor has the effect of gender on this correlation, been clear. We, therefore, aimed to assess the correlation between levels of WBC, platelet count, ESR and CRP with three stages of abnormal BMI, i.e., overweight, obesity and morbid obesity. This was investigated separately for men and women, using data from a large cohort of subjects attending a screening center.

\section{Methods}

\section{Study Population}

The study population was taken from a medical screening clinic of people routinely referred by their workplace to a tertiary medical center in central Israel, from 2000 until 2014. Thus, the study sample was cross-sectional. It was ambulatory, and made up of men and (non-pregnant) women between the ages of 20 and 80 years. The screening began with a detailed medical history. A comprehensive physical examination was followed by a range of blood and urine tests; blood tests were carried out after fasting overnight for 12 hours. In addition, each participant had a chest X ray, an electrocardiogram, an exercise stress test, and underwent a respiratory function test, as well as a full ophthalmology examination. Data from each person's latest appointment was used in the study. Information on smoking habits was recorded on the day of examination by direct questioning.

WBC and platelet count were performed on ADVIA 120 coulter and on ADVIA 2120 coulter manufactured by SIEMENS $^{\circledR}$, since 2015; the method used was flow cytometry. The ESR levels were assessed by the Wintrobe method using EDTA anticoagulated blood. High sensitive method for measuring CRP was used using the Beckman coulter OLYMPUS AU 2700 analyzer.
Subjects who smoked, and those on corticosteroid treatment were excluded from the analysis, as well as subjects with hemoglobin levels less than $10 \mathrm{gr} / \mathrm{dl}$.

The BMI categories were divided into four groups: Normal $=18.5-<25 \mathrm{~kg} / \mathrm{m}^{2} ;$ overweight $=25-29.9 \mathrm{~kg} /$ $\mathrm{m}^{2}$; obesity $=30-<35 \mathrm{~kg} / \mathrm{m}^{2}$ and morbid obesity $=\geq 35$ $\mathrm{kg} / \mathrm{m}^{2}$. Abnormal levels of the four inflammatory markers were defined as follows: WBC above 10,000 per cubic millimeter; PLT above 400,000 per cubic millimeter; ESR above $15 \mathrm{~mm}$ for men and above $20 \mathrm{~mm}$ for women at the first hour, and CRP above $0.5 \mathrm{mg} / \mathrm{dl}$.

Data collected from each visit was entered into a spreadsheet created in Excel for the purpose of the study. This computer program was also used to carry out statistical analysis of the data. The identifying numbers of all those taking part were coded ahead of the analysis. As the data were anonymized, the Helsinki Ethics Committee of Rabin Medical Center, Israel gave their approval for the study with no need for informed consent from participants.

\section{Statistical Analysis}

Baseline characteristics were compared between men and women using Student's $t$-test and chi-square test for continuous and categorical variables, respectively. The odds ratios (ORs) and 95\% CI comparing subjects with either overweight, or obesity or morbid obesity, to subjects with normal BMI as to four inflammatory markers were assessed by using a logistic regression method. Univariate analyses were performed in Model 1. Model 2 was adjusted for age alone; and Model 3 was adjusted for age, diabetes mellitus, hypertension and kidney function.

For all analyses, a p-value of $<0.05$ was considered significant. All analyses were performed using SAS v. 9.4.

\section{Results}

The cross-sectional analysis included 10,745 subjects, 7526 men and 3219 women (30\%). The clinical and laboratory characteristics of the participants, according to gender, are presented in Table 1. Women in this sample were slightly older than men and had more favorable clinical and laboratory results compared to men. As for the inflammatory markers, WBC levels were similar for both sexes but all other inflammatory markers were found to be significantly higher in women.

Table 2 shows data of mean levels of the different inflammatory markers in each BMI category. It can clearly be seen that as the BMI increases so do the levels of 
Table I Patients Characteristics by Gender

\begin{tabular}{|c|c|c|c|}
\hline & Men $\mathbf{N}=7526$ & Women $\mathrm{N}=3219$ & $P$ value \\
\hline Age (years), mean (SD) & $47.5(9.7)$ & $46.7(9.8)$ & $<0.001$ \\
\hline BMI $\left(\mathrm{kg} / \mathrm{m}^{2}\right)$, mean $(\mathrm{SD})$ & $27.2(3.9)$ & $25.5(4.7)$ & $<0.001$ \\
\hline Waist circumference $(\mathrm{cm})$, mean $(\mathrm{SD})$ & $92.8(11.1)$ & $79.8(10.9)$ & $<0.001$ \\
\hline Systolic BP (mmHg), mean (SD) & $120.9(13.1)$ & II $2.4(13.6)$ & $<0.001$ \\
\hline Diastolic BP (mmHg), mean (SD) & $78.8(7.5)$ & $73.8(8.0)$ & $<0.001$ \\
\hline Hypertension (\%) & 13.8 & 6.2 & $<0.001$ \\
\hline Hyperuricemia (\%) & 16.4 & 3.8 & $<0.001$ \\
\hline eGFR (CKD-EPI) mL/min/l.73 $\mathrm{m}^{2}$, mean (SD) & 95.7 (13.9) & $101.0(13.8)$ & $<0.001$ \\
\hline Serum glucose concentration $(\mathrm{mg} / \mathrm{dl})$, mean $(\mathrm{SD})$ & $99.8(16.2)$ & $94.2(12.2)$ & $<0.001$ \\
\hline Diabetes Mellitus (\%) & 4.4 & 2.5 & $<0.001$ \\
\hline WBC $\left(10^{3}\right.$ per cubic $\left.\mathrm{mm}\right)$ mean $(\mathrm{SD})$ & $6.5(1.5)$ & $6.5(1.6)$ & 0.243 \\
\hline PLT $\left(10^{3}\right.$ per cubic $\left.\mathrm{mm}\right)$ mean $(\mathrm{SD})$ & $218.5(51.0)$ & $244.7(60.2)$ & $<0.001$ \\
\hline ESR (mm/hour) mean (SD) & $8.6(2.0)$ & II.8 (2.0) & $<0.001$ \\
\hline CRP (mg/dl) mean (SD) & $0.26(0.42)$ & $0.31(0.48)$ & $<0.001$ \\
\hline Total Cholesterol (mg/dl), mean (SD) & $191.3(35.0)$ & $195.4(37.2)$ & $<0.001$ \\
\hline Triglycerides (mg/dl), mean (SD) & $130.2(75.2)$ & $102.5(67.1)$ & $<0.001$ \\
\hline LDL cholesterol (mg/dl), mean (SD) & $117.6(30.0)$ & II $4.3(30.0)$ & $<0.001$ \\
\hline HDL cholesterol (mg/dl), mean (SD) & $48.2(10.2)$ & $60.7(13.5)$ & $<0.001$ \\
\hline Dyslipidemia (\%) & 52.2 & 55.0 & 0.003 \\
\hline Metabolic syndrome (\%) & 17.5 & 10.2 & $<0.001$ \\
\hline
\end{tabular}

Table 2 Inflammation Factors and Body Mass Index Category

\begin{tabular}{|c|c|c|c|c|c|}
\hline \multirow[t]{4}{*}{ Inflammation Factors } & \multirow[t]{2}{*}{ Gender } & \multicolumn{4}{|c|}{ Body Mass Index Category $\left(\mathrm{kg} / \mathrm{m}^{2}\right)$} \\
\hline & & $18.5-<25$ & $25-<30$ & $30-<35$ & $\geq 35$ \\
\hline & Men & 2291 & 3753 & 1166 & 316 \\
\hline & Women & 1782 & 960 & 339 & 138 \\
\hline WBC $\left(10^{3}\right.$ per cubic $\left.\mathrm{mm}\right)$ mean $(\mathrm{SD})$ & $\begin{array}{l}\text { Men } \\
\text { Women }\end{array}$ & $\begin{array}{l}6.2(1.4) \\
6.3(1.5)\end{array}$ & $\begin{array}{l}6.5(1.4)^{\mathrm{a}} \\
6.6(1.6)^{\mathrm{a}}\end{array}$ & $\begin{array}{l}7.0(1.5)^{\mathrm{a}} \\
7.0(1.7)^{\mathrm{a}}\end{array}$ & $\begin{array}{l}7.6(1.7)^{\mathrm{a}} \\
7.5(1.8)^{\mathrm{a}}\end{array}$ \\
\hline Thrombocytes $\left(10^{3}\right.$ per cubic $\left.\mathrm{mm}\right)$ mean $(\mathrm{SD})$ & $\begin{array}{l}\text { Men } \\
\text { Women }\end{array}$ & $\begin{array}{l}213.8(50.1) \\
240.3(57.7)\end{array}$ & $\begin{array}{l}217.9(50.2)^{c} \\
243.5(60.3)^{d}\end{array}$ & $\begin{array}{l}225.3(51.9)^{\mathrm{a}} \\
264.7(66.7)^{\mathrm{a}}\end{array}$ & $\begin{array}{l}233.9(56.7)^{\mathrm{b}} \\
261.0(62.8)^{\mathrm{b}}\end{array}$ \\
\hline ESR (mm/hour) mean (SD) & $\begin{array}{l}\text { Men } \\
\text { Women }\end{array}$ & $\begin{array}{l}10(8) \\
18(10)\end{array}$ & $\begin{array}{l}11(8)^{\mathrm{a}} \\
22(12)^{\mathrm{a}}\end{array}$ & $\begin{array}{l}14(10)^{\mathrm{a}} \\
25(13)^{\mathrm{a}}\end{array}$ & $\begin{array}{l}18(12)^{\mathrm{a}} \\
31(16)^{\mathrm{a}}\end{array}$ \\
\hline CRP $(\mathrm{mg} / \mathrm{dl})$ mean $(\mathrm{SD})$ & $\begin{array}{l}\text { Men } \\
\text { Women }\end{array}$ & $\begin{array}{l}0.2(0.4) \\
0.2(0.4)\end{array}$ & $\begin{array}{l}0.2(0.3)^{\mathrm{a}} \\
0.3(0.4))^{\mathrm{a}}\end{array}$ & $\begin{array}{l}0.4(0.4)^{\mathrm{a}} \\
0.5(0.7)^{\mathrm{a}}\end{array}$ & $\begin{array}{l}0.7(1.0)^{\mathrm{a}} \\
0.9(0.7)^{\mathrm{a}}\end{array}$ \\
\hline
\end{tabular}

Notes: P value comparing the overweight, obesity and morbid obesity group to the normal BMI group. ${ }^{a} p<0.0001$; ${ }^{b} p<0.001 ;{ }^{c} p<0.01$; ${ }^{d}$ not significant.

inflammatory markers. This was found to be true for both men and women.

Tables 3 and 4 represent the OR of the prevalence of increased inflammatory markers; it compares subjects who are overweight, obese and morbidly obese to subjects with normal BMI, for men and women, respectively. The data are presented as a crude OR comparison as well as for OR adjusted for age (Model 1) and for age, diabetes mellitus, hypertension and eGFR (Model 2).

In men; OR for elevated levels of WBC was found to be significant in obese and morbidly obese subjects, compared to subjects with normal BMI; OR for elevated platelet levels, however, was not found to be significant in all the above normal BMI groups, compared to 
Table 3 Men's Odds Ratio Comparing the Prevalence of Increased Inflammatory Marker Between Subjects with Overweight, Obese and Morbid Obesity and Subjects with Normal BMI

\begin{tabular}{|c|c|c|c|}
\hline \multirow[t]{2}{*}{ Inflammation Factors } & \multicolumn{3}{|c|}{ Body Mass Index Category $\left(\mathrm{kg} / \mathrm{m}^{2}\right)$} \\
\hline & $25-<30$ & $30-<35$ & $\geq 35$ \\
\hline \multicolumn{4}{|c|}{ WBC $>10\left(10^{3}\right.$ per cubic $\left.\mathrm{mm}\right)$} \\
\hline Crude & $1.2(0.8-1.9)$ & $1.9(1.2-3.0)$ & $6.3(3.8-10.5)$ \\
\hline Model I & $1.3(0.9-1.9)$ & $2.0(1.2-3.2)$ & $6.6(3.9-10.8)$ \\
\hline Model 2 & $1.3(0.8-1.9)$ & $\mathrm{I} .8(1 . \mathrm{I}-2.9)$ & $5.1(2.9-8.7)$ \\
\hline \multicolumn{4}{|c|}{ Thrombocytes $>400\left(10^{3}\right.$ per cubic $\left.\mathrm{mm}\right)$} \\
\hline Crude & I.I $(0.4-2.6)$ & I.7 (0.6-5.0) & $2.1(0.4-10.1)$ \\
\hline Model I & $0.9(0.4-2.4)$ & I.4 (0.5-4.3) & $1.8(0.4-8.9)$ \\
\hline Model 2 & $0.9(0.4-2.4)$ & I. $4(0.4-4.2)$ & $1.7(0.3-8.5)$ \\
\hline \multicolumn{4}{|l|}{ ESR $>15$ (mm/hour) } \\
\hline Crude & $1.5(1.3-1.7)$ & $2.7(2.3-3.2)$ & $5.0(3.9-6.4)$ \\
\hline Model I & $1.3(1.2-1.5)$ & $2.3(2.0-2.7)$ & $4.6(3.6-5.9)$ \\
\hline Model 2 & $1.3(1.2-1.5)$ & $2.3(2.0-2.7)$ & $4.2(3.2-5.4)$ \\
\hline \multicolumn{4}{|l|}{ CRP $>0.5 \mathrm{mg} / \mathrm{dl}$} \\
\hline Crude & $1.8(1.5-2.2)$ & $4.0(3.2-5.1)$ & $13.4(10.1-17.9)$ \\
\hline Model I & $1.9(1.5-2.4)$ & $4.4(3.4-5.5)$ & $14.3(10.8-19.2)$ \\
\hline Model 2 & $1.9(1.5-2.4)$ & $4.3(3.4-5.5)$ & $13.4(10.0-18.2)$ \\
\hline
\end{tabular}

Table 4 Women's Odds Ratio Comparing the Prevalence of Increased Inflammatory Marker Between Subjects with Overweight, Obese and Morbid Obesity and Subjects with Normal BMI

\begin{tabular}{|c|c|c|c|}
\hline \multirow[t]{2}{*}{ Inflammation Factors } & \multicolumn{3}{|c|}{ Body Mass Index Category $\left(\mathrm{kg} / \mathrm{m}^{2}\right)$} \\
\hline & $25-<30$ & $30-<35$ & $\geq 35$ \\
\hline \multicolumn{4}{|c|}{ WBC $>10\left(10^{3}\right.$ per cubic $\left.\mathrm{mm}\right)$} \\
\hline Crude & $1.6(1.0-2.5)$ & $2.6(1.5-4.5)$ & $4.7(2.5-8.8)$ \\
\hline Model I & $\mathrm{I} .8(\mathrm{I} . \mathrm{I}-2.8)$ & $3.0(1.7-5.3)$ & $5.3(2.8-10.1)$ \\
\hline Model 2 & $\mathrm{I} .8(\mathrm{I} . \mathrm{I}-2.8)$ & $2.8(1.6-5.0)$ & $4.7(2.4-9.1)$ \\
\hline \multicolumn{4}{|c|}{ Thrombocytes $>400\left(10^{3}\right.$ per cubic $\left.\mathrm{mm}\right)$} \\
\hline Crude & $1.5(0.8-2.9)$ & $3.7(1.8-7.6)$ & $2.1(0.6-7.1)$ \\
\hline Model I & $1.6(0.8-3.1)$ & $4.0(1.9-8.3)$ & $2.2(0.6-7.6)$ \\
\hline Model 2 & $\mathrm{I} .5(0.8-3.0)$ & $3.9(1.8-8.2)$ & $2.0(0.6-7.2)$ \\
\hline \multicolumn{4}{|l|}{ ESR $>20$ (mm/hour) } \\
\hline Crude & $1.9(1.6-2.2)$ & $2.8(2.2-3.5)$ & $8.8(3.4-7.0)$ \\
\hline Model I & $\mathrm{I} .8(1.5-2.1)$ & $2.6(2.0-3.3)$ & $4.6(3.2-6.6)$ \\
\hline Model 2 & $\mathrm{I} .8(\mathrm{I} .5-2 . \mathrm{I})$ & $2.6(2.0-3.3)$ & $4.6(3.2-6.6)$ \\
\hline \multicolumn{4}{|l|}{ CRP $>0.5 \mathrm{mg} / \mathrm{dl}$} \\
\hline Crude & $2.1(1.6-2.6)$ & $4.9(3.7-6.5)$ & $16.4(11.3-24.1)$ \\
\hline Model I & $1.9(1.5-2.4)$ & $4.4(3.4-5.5)$ & $14.4(10.7-19.2)$ \\
\hline Model 2 & $2.3(1.9-3.0)$ & $5.9(4.4-7.9)$ & $19.2(12.9-28.6)$ \\
\hline
\end{tabular}

subjects with normal BMI. The OR of increased ESR was only found to be statistically significant in the group with morbid obesity compared to those with normal BMI. The OR of increased CRP was found to be significant for all groups of increased BMI, compared to subjects with normal BMI. 
Table 5 Gender Comparison of Inflammation Factors in Subjects with BMI $\geq 30 \mathrm{~kg} / \mathrm{m}^{2}$

\begin{tabular}{|c|c|c|c|}
\hline Inflammation Factors & Men $N=\mid 482$ & Women $N=477$ & $\mathbf{P}$ value \\
\hline WBC $\left(10^{3}\right.$ per cubic $\left.\mathrm{mm}\right)$ mean $(\mathrm{SD})$ & $7.1(1.5)$ & $7.1(1.8)$ & 0.915 \\
\hline Thrombocytes $\left(10^{3}\right.$ per cubic $\left.\mathrm{mm}\right)$ mean (SD) & $227.1(53.0)$ & $263.7(65.5)$ & $<0.001$ \\
\hline ESR ( $\mathrm{mm}$ at the first hour) mean (SD) & $15(10)$ & $27(15)$ & $<0.001$ \\
\hline CRP (mg/dl) mean (SD) & $0.4(0.6)$ & $0.6(0.7)$ & $<0.001$ \\
\hline
\end{tabular}

In women; OR for elevated levels of WBC was found to be significant in all groups of increased BMI, compared to subjects with normal BMI; while OR for elevated platelet levels was only found to be significant in the obese group, compared to subjects with normal BMI. The OR of increased ESR, and increased CRP, was found to be significant in all groups of increased BMI, compared to subjects with normal BMI.

As for gender differences for inflammatory markers, as can be seen from Table 1 for women, all parameters of inflammation were found to be significantly higher than in men, apart from WBC average levels. In addition, the percentage of elevated inflammatory markers was significantly higher in women. These differences remained after adjusting for age, diabetes mellitus, hypertension and eGFR ( $p<0.0003)$. Lastly, in the group with BMI $\geq 30$ all parameters of inflammation were found to be significantly higher in women, apart from the levels of WBC (Table 5).

\section{Discussion}

In this large cohort, of 10,745 subjects attending a screening center for routine annual examination, we show the results of four simple laboratory tests of markers of inflammation, i.e., levels of WBC, platelets, ESR and CRP. These were found to increase as BMI increases. This was found to be true for all four tests but was most prominent in relation to the CRP inflammatory marker. Unsurprisingly, this correlation was greatest in the group with morbid obesity. Gender differences were found to favor men.

As mentioned, in the methods and statistical analysis section, there are factors that may affect the levels of inflammatory markers independent of obesity. Therefore, the following subjects were excluded: those who had a history of smoking, on prescribed corticosteroids or with anemia. As diabetes mellitus, ${ }^{18}$ hypertension ${ }^{19}$ and decreased kidney function ${ }^{20}$ are related to increased levels of inflammation, the regression analysis included these three conditions as well as in addition to age adjustment.

How might obesity lead to inflammation? In a review article, Hernandez et $\mathrm{al}^{21}$ observe that chronic diseases are characterized by increased levels of acute-phase reactants such as fibrinogen, CRP, complement, serum amyloid A and haptoglobin. ${ }^{2}$ These reactants are produced by the liver and are regulated by cytokines including IL- 6 and TNF-alpha. ${ }^{3-5}$ Adipocytes express and secrete TNF-alpha, which may account for the relationship between obesity and inflammation. ${ }^{22}$ Another pro-inflammatory cytokine synthesized by adipose tissue is IL- 6 , and the CRP produced in the liver is largely a response to IL- 6 stimuli. ${ }^{23}$ Indeed, in recent years it has been shown that in healthy obese subjects there are increasing levels of pro-inflammatory cytokines such as IL- 6 and TNF alpha and as a result, high levels of acute-phase reactants such as CRP and haptoglobin. ${ }^{6-8}$ Moreover, weight loss through diet is associated with reduction in circulating levels of IL-6, TNF alpha and CRP. ${ }^{24,25}$ Similar results have been found in subjects after gastric bypass surgery. ${ }^{9,10}$

Why do obese women have higher levels of inflammatory markers compared to men? Several theoretical explanations may be offered. ${ }^{11}$ Women have more subcutaneous fat compared to men, who have fat localized to the intra-abdominal deposits. This may account for the different levels of inflammation between sexes. Secondly, sex hormones affect the circulating levels of inflammatory proteins; certainly postmenopausal hormonal replacement treatment has been shown to be associated with increase CRP concentrations. ${ }^{26,27}$ Another possible explanation for gender differences regarding CRP is the relationship between leptin levels and CRP. ${ }^{28}$ Previous studies have reported higher levels of CRP and leptin in women compared to men. ${ }^{29}$

Do our results shed new light on what is known in the literature? The effect of leukocytosis in obese individuals was assessed by Herishanu et al. ${ }^{12}$ They evaluated 327 patients who were referred to a hematology clinic for the further investigation of persistent leukocytosis. Fifty patients, most of whom were women, were found to be obese with no other possible explanations for the leukocytosis. Follow-up at 45.6 months of these subjects did not show any new possible cause that could account leukocytosis other than obesity.

The level of platelets in relation to obesity has been investigated by Samocha-Bonet et al. ${ }^{13}$ In a study of 6319 subjects, they found that platelet count rose in relation to BMI, for both 
genders. Only among women, however, were the platelet counts found to be significantly elevated in the overweight, obese and morbidly obese subgroups. This was after adjustment for age, diabetes mellitus and hypertension. De Pergola et $\mathrm{al}^{30}$ were the first to show a strong positive and independent relationship between platelet count and $\mathrm{HbA1C}$. This was shown in 240 non diabetic, overweight and obese subjects. In another paper, however, De Pergola et $\mathrm{al}^{31}$ showed carotid intima media thickness to be negatively correlated with platelet count. This was shown in 961 subjects, of whom $87.4 \%$ were either overweight or obese. They suggested that this inverse association may reflect a compensatory mechanism to protect against atherothrombotic diseases, at least in people with excessive fat.

Regarding ESR and BMI, three small studies have produced conflicting results. Pasulka et $\mathrm{al}^{32}$ screened 24 morbidly obese patients planned for gastric bypass surgery. They noticed that 11 out of 20 women, and 2 out of 4 men had ESR levels above upper limits of normal ( $20 \mathrm{~mm} / \mathrm{h}$ for women and $10 \mathrm{~mm} / \mathrm{h}$ for men). Seven patients had rates of $40 \mathrm{~mm} / \mathrm{r}$ or more. None of the subjects had underlying inflammatory conditions. In another study, Leff et $\mathrm{al}^{33}$ compared 12 patients who were $45 \mathrm{~kg}$ over ideal weight to 13 patients with normal weight. None of the patients had any history of inflammatory process or significant anemia. The mean ESR in the obese group was $17 \mathrm{~mm} / \mathrm{h}$, and was found to be significantly higher than that of the control group $4 \mathrm{~mm} / \mathrm{h} \quad(\mathrm{p}=0.015)$. Meanwhile, Richter et $\mathrm{al}^{34}$ assessed 31 obese persons (26 women) and compared them to 20 subjects of normal weight. The serum and hematological values were normal for both groups. Yet the ESR in the obese group was found to be $7.8(5.3) \mathrm{mm} / \mathrm{h}$, compared with $3.6(3.1) \mathrm{mm} / \mathrm{h}$ in the group with normal weight. He concluded that obese persons who are healthy do not have ESR levels beyond the upper limit of normal.

Lastly, with regard to CRP and the effect of obesity, Coi et $\mathrm{al}^{15}$ performed a systematic review and meta-analysis of all cross-sectional studies relating to CRP and obesity. Out of over 4000 potential papers, 51 studies met their inclusion criteria. Overall, the Pearson coefficient between BMI and ln (CRP) was found to be strong $0.36(95 \% \mathrm{CI}=0.30-0.42)$. Similarly, the Pearson coefficient between waist circumference and $\ln$ (CRP) was 0.40 $(95 \% \mathrm{CI}=0.31-0.48)$. In addition, the association between CRP and BMI, in the meta-regression models performed, showed a stronger association in women compared to men.
The main strength of this study is the inclusion of a large cohort of 10,745 males and females with complete datasets of clinical and laboratory findings. Nevertheless, our study has its limitations. The study group was drawn from a clinical sample of subjects attending a screening center and this limits the generalizability of the findings. In our study, we found a relationship between inflammatory markers and BMI. As fat distribution seems to be more important than BMI, it might have been more appropriate to assess the relationship of inflammatory markers to an anthropometric parameter such as neck circumference, or waist to height ratio. ${ }^{35}$ Lastly, data on the percentage of subjects on medication was not included in the results.

In summary, in this large cohort we clearly show four routine markers of inflammation to be correlated with BMI. This was especially found to be true in the morbidly obese group. Gender differences were found in favor of men. The general practitioner or physician should not be surprised by the lab results of a morbidly obese man or woman with abnormally high levels of inflammatory markers. Clinicians should exercise careful judgment before deciding on further investigations that might be unnecessary and costly.

\section{Disclosure}

The authors report no conflicts of interest for this work.

\section{References}

1. Mitchell NS, Catenacci VA, Wyatt HR, Hill JO. Obesity: overview of an epidemic. Psychiatr Clin North Am. 2011;34(4):717-732. doi:10.1016/j.psc.2011.08.005

2. Pickup JC. Inflammation and activated innate immunity in the pathogenesis of type 2 diabetes. Diabetes Care. 2004;27(3):813-823. doi:10.2337/diacare.27.3.813

3. Gabay C, Kushner I, Epstein FH. Acute-phase proteins and other systemic responses to inflammation. $N$ Engl J Med. 1999;340 (6):448-454. doi:10.1056/NEJM199902113400607

4. Yudkin JS, Kumari M, Humphries SE, Mohamed-Ali V. Inflammation, obesity, stress and coronary heart disease: is interleukin-6 the link? Atherosclerosis. 2000;148(2):209-214. doi:10.1016/S0021-9150(99) 00463-3

5. Yudkin JS. Adipose tissue, insulin action and vascular disease: inflammatory signals. Int J Obes Relat Metab Disord. 2003;27(Suppl 3):S25S28. doi:10.1038/sj.ijo.0802496

6. Caballero AE. Endothelial dysfunction in obesity and insulin resistance: a road to diabetes and heart disease. Obes Res. 2003;11 (11):1278-1289. doi:10.1038/oby.2003.174

7. Berg AH, Scherer PE. Adipose tissue, inflammation, and cardiovascular disease. Circ Res. 2005;96(9):939-949. doi:10.1161/01. RES.0000163635.62927.34

8. Lau DC, Dhillon B, Yan H, Szmitko PE, Verma S. Adipokines: molecular links between obesity and atheroslcerosis. Am J Physiol Heart Circ Physiol. 2005;288(5):H2031-H2041. doi:10.1152/ ajpheart.01058.2004 
9. Askarpour M, Khani D, Sheikhi A, Ghaedi E, Alizadeh S. Effect of bariatric surgery on serum inflammatory factors of obese patients: a systematic review and meta-analysis. Obes Surg. 2019;29(8):26312647. doi:10.1007/s11695-019-03926-0

10. Askarpour M, Alizadeh S, Hadi A, et al. Effect of bariatric surgery on the circulating level of adiponectin, chemerin, plasminogen activator inhibitor-1, leptin, resistin, and visfatin: a systematic review and meta-analysis. Horm Metab Res. 2020;52(4):207-215. doi:10.1055/ a-1129-6785

11. Festa A, D'agostino jr R Jr, Williams K, et al. The relation of body fat mass and distribution to markers of chronic inflammation. Int $J$ Obes Relat Metab Disord. 2001;25(10):1407-1415. doi:10.1038/sj. ijo.0801792

12. Herishanu Y, Rogowski O, Polliack A, Marilus R. Leukocytosis in obese individuals: possible link in patients with unexplained persistent neutrophilia. Eur J Haematol. 2006;76(6):516-520. doi:10.1111/ j.1600-0609.2006.00658.x

13. Samocha-Bonet D, Justo D, Rogowski O, et al. Platelet counts and platelet activation markers in obese subjects. Mediators Inflamm. 2008;2008:834153. doi:10.1155/2008/834153

14. George MD, Giles JT, Katz PP, et al. Impact of obesity and adiposity on inflammatory markers in patients with rheumatoid arthritis. Arthritis Care Res. 2017;69(12):1789-1798. doi:10.1002/acr.23229

15. Choi J, Joseph L, Pilote L. Obesity and C-reactive protein in various populations: a systematic review and meta-analysis. Obes Rev. 2013;14(3):232-244. doi:10.1111/obr.12003

16. Paepegaey AC, Genser L, Bouillot JL, Oppert JM, Clement K, Poitou C. High levels of CRP in morbid obesity: the central role of adipose tissue and lessons for clinical practice before and after bariatric surgery. Surg Obes Relat Dis. 2015;11(1):148-154. doi:10.1016/j. soard.2014.06.010

17. Randell EW, Twells LK, Gregory DM, et al. Pre-operative and postoperative changes in CRP and other biomarkers sensitive to inflammatory status in patients with severe obesity undergoing laparoscopic sleeve gastrectomy. Clin Biochem. 2018;52:13-19. doi:10.1016/j. clinbiochem.2017.10.010

18. Wang X, Bao W, Liu J, et al. Inflammatory markers and risk of type 2 diabetes: a systematic review and meta-analysis. Diabetes Care. 2013;36(1):166-175. doi:10.2337/dc12-0702

19. Pauletto P, Rattazzi M. Inflammation and hypertension: the search for a link. Nephrol Dial Transplant. 2006;21(4):850-853. doi:10.1093/ ndt/gfl019

20. Shankar A, Sun L, Klein BE, et al. Markers of inflammation predict the long-term risk of developing chronic kidney disease: a population-based cohort study. Kidney Int. 2011;80(11):1231-1238. doi:10.1038/ki.2011.283

21. Rodriguez-Hernandez H, Simental-Mendia LE, Rodriguez-Ramirez G, Reyes-Romero MA. Obesity and inflammation: epidemiology, risk factors, and markers of inflammation. Int $J$ Endocrinol. 2013;2013:678159. doi:10.1155/2013/678159

22. Kern PA, Saghizadeh M, Ong JM, Bosch RJ, Deem R, Simsolo RB. The expression of tumor necrosis factor in human adipose tissue. Regulation by obesity, weight loss, and relationship to lipoprotein lipase. J Clin Invest. 1995;95(5):2111-2119. doi:10.1172/JCI117899
23. Laaksonen DE, Niskanen L, Nyyssonen K, et al. C-reactive protein and the development of the metabolic syndrome and diabetes in middle-aged men. Diabetologia. 2004;47(8):1403-1410. doi:10.1007 /s00125-004-1472-x

24. Heilbronn LK, Noakes M, Clifton PM. Energy restriction and weight loss on very-low-fat diets reduce $\mathrm{C}$-reactive protein concentrations in obese, healthy women. Arterioscler Thromb Vasc Biol. 2001;21 (6):968-970. doi:10.1161/01.ATV.21.6.968

25. Nicoletti G, Giugliano G, Pontillo A, et al. Effect of a multidisciplinary program of weight reduction on endothelial functions in obese women. $J$ Endocrinol Invest. 2003;26(3):RC5-RC8. doi:10.1007/BF03345154

26. Ridker PM, Hennekens CH, Rifai N, Buring JE, Manson JE. Hormone replacement therapy and increased plasma concentration of C-reactive protein. Circulation. 1999;100(7):713-716. doi:10.116 1/01.CIR.100.7.713

27. Cushman M, Legault C, Barrett-Connor E, et al. Effect of postmenopausal hormones on inflammation-sensitive proteins: the Postmenopausal Estrogen/Progestin Interventions (PEPI) Study. Circulation. 1999;100(7):717-722. doi:10.1161/01.CIR.100.7.717

28. Abdullah SM, Khera A, Leonard D, et al. Sex differences in the association between leptin and CRP: results from the Dallas Heart Study. Atherosclerosis. 2007;195(2):404-410. doi:10.1016/j. atherosclerosis.2006.10.022

29. Saad MF, Damani S, Gingerich RL, et al. Sexual dimorphism in plasma leptin concentration. J Clin Endocrinol Metab. 1997;82 (2):579-584. doi:10.1210/jcem.82.2.3739

30. De Pergola G, Giagulli VA, Guastamacchia E, et al. Platelet number is positively and independently associated with glycated hemoglobin in non-diabetic overweight and obese subjects. Nutr Metab Cardiovasc Dis. 2019;29(3):254-259. doi:10.1016/j.numecd.201 8.12.007

31. De Pergola G, Zupo R, Cecere A, et al. Platelet number is negatively and independently associated with carotid intima-media thickness in apparently healthy overweight/obese subjects. Nutr Metab Cardiovasc Dis. 2018;28(12):1217-1221. doi:10.1016/j.numecd .2018 .08 .001

32. Pasulka PS, Bistrian BR, Blackburn GL. Obesity and erythrocyte sedimentation rates. Ann Intern Med. 1985;103(2):304. doi:10.7326/ 0003-4819-103-2-304 1

33. Leff RD, Akre SP. Obesity and the erythrocyte sedimentation rate. Ann Intern Med. 1986;105(1):143. doi:10.7326/0003-4819-105-11432

34. Richter WO, Mohrle W, Schwandt P. Obesity and the erythrocyte sedimentation rate. Ann Intern Med. 1988;109(11):928-929. doi:10.7326/0003-4819-109-11-928

35. Lampignano L, Zupo R, Donghia R, et al. Cross-sectional relationship among different anthropometric parameters and cardio-metabolic risk factors in a cohort of patients with overweight or obesity. PLoS One. 2020;15(11):e241841. doi:10.1371/journal.pone.02 41841 mechanisms; pharmacology and novel anti-inflammatory drugs; clinical conditions involving inflammation. The manuscript management system is completely online and includes a very quick and fair peerreview system. Visit http://www.dovepress.com/testimonials.php to read real quotes from published authors.
Journal of Inflammation Research

\section{Publish your work in this journal}

The Journal of Inflammation Research is an international, peerreviewed open-access journal that welcomes laboratory and clinica findings on the molecular basis, cell biology and pharmacology of inflammation including original research, reviews, symposium reports, hypothesis formation and commentaries on: acute/chronic inflammation; mediators of inflammation; cellular processes; molecular
Dovepress

Submit your manuscript here: https://www.dovepress.com/journal-of-inflammation-research-journal 